\title{
Monitoring and Evaluation Practices and Performance of livelihood ventures: Focus; Nairobi youths conservation projects, Kenya
}

Nderitu B. Wanjiru

Africa Nazarene University, Nairobi

\section{Dorothy Ndunge Kyalo}

University of Nairobi, School of Open and Distance Learning, KIKUYU

\section{Angeline Sabina Mulwa}

Senior Lecturer, School of Open \& Distance e-Learning, University of Nairobi, KIKUYU

\section{John Mbugua}

Senior Lecturer, School of Open Distance Learning, ODeL Campus, University of Nairobi, KIKUYU

Submitted: 25 September 2020

Accepted: 27 October 2020

Published: 30 November 2020

Corresponding author:

Wanjiru Nderitu

DOI: 10.19044/esj.2020.v16n31p300

(c) Copyright 2020 Wanjiru Nderitu et al. Distributed under Creative Commons BY-NC-ND 4.0 OPEN ACCESS
Abstract
In Kenya, youth unemployment rate is on
the rise especially for urban youths,
despite government's perennial interventions and funding. This study sought to investigate on monitoring and evaluation practices and performance of livelihood ventures; focusing on youth conservation projects in Nairobi County. The study specifically focused on solid waste collection projects managed by youth groups within Nairobi residential areas; which is among the conservation projects that attract government funding through the Directorate of youth. The study had a target population of 700 youth group members and a Study sample of 248 youths. Key informants from 4 departments of Directorate of Youth affairs were purposely selected. The study adopted descriptive survey and correlational research designs where data was collected using questionnaire and focus group discussion guide. Qualitative data was analyzed and presented in narrative statements while inferential statistics were analyzed using Pearson correlation coefficient and multiple regression analysis to test hypotheses. The research formulated a hypotheses in null state and subsequently, F-Test was used test it portraying; $\mathrm{r}(247)=.196, \mathrm{R} 2 \mathrm{0.38}$, $\mathrm{F}(5,242)=9.777 \mathrm{p} \leq .05$, implying that the levels of monitoring and evaluation practices possessed by youths may be a good predictor of performance of youth conservation projects. This inferred to the rejection of the null hypothesis and the conclusion made that $\mathrm{H} 1$ : There is a significant relationship between monitoring and evaluation practices and performance of youth solid waste

How to cite this article

Wanjiru N. et al. (2020). Monitoring and Evaluation Practices and Performance of livelihood ventures: Focus; Nairobi youths conservation projects, Kenya. European Scientific Journal, ESJ, 16(31), 300. https://doi.org/10.19044/esj.2020.v16n31p300 
management projects in Nairobi County. The study findings provided the evidence that the level of performance increases as monitoring and evaluation practices intensifies. The researcher recommends a Policy action by government to incorporate youths to obtain and nature monitoring and evaluation skills through industrial attachments in National and
County entities dealing with conservation projects; to enhance gainful youth conservation projects.

\section{Subject: Waste Management}

Keywords: Monitoring and evaluation practices, Livelihood projects, solid waste management projects, performance of youth conservation project

\section{Introduction}

Global youth unemployment rate currently stands at 13\%, (ILO, 2018). Kenya's population is reported to comprise of 75 percent youth with overall youth unemployment rate reported at 7.4 percent by the end of the year 2019 (Awiti, 2016). Environment offers context for alienated youth, towards reengaging in gainful conservation projects that improves their livelihoods (Achankeng, 2003). This would gainfully benefit the bulging number of jobless youths, particularly low-income urban youth; to enable them find positive and meaningful ways to engage in conservation projects by reducing the amount of solid waste that has been dumped or burnt while creating meaningful jobs that can improve their livelihoods (ILO, 2017

Monitoring and evaluation (M\&E) is increasingly becoming an essential program management tool. This study consequently alludes to post positivism and critical postmodernism perspectives in support of different M\&E constructivist philosophies (Connell, JP, Kubisch, 1998). It explores monitoring and evaluation practices based on axiological and ontological assumptions of cultural responsive approaches that demonstrates how well youth connects with conservation livelihood projects. Monitoring involves a systematic collection of information about activities while evaluation is an assessment of characteristics and results of projects or programmes to make judgment on whether to improve, inform decisions and increase the understanding of the programs processes (Patton, 2008).

These various definitions depicts $\mathrm{M} \& \mathrm{E}$ as an ongoing process mainly based on the set targets and planned activities in the course of the planning stage of work. Various agencies (The UN in particular) have established fullfledged M \& E departments and legal or regulatory frameworks for regular $M \& E$ execution of projects that are donor funded on the backdrop of stringent regulations to achieve purposed socio economic development in target beneficiary communities. There is an increase in the amount of systematic attention and study being applied to the field of monitoring and evaluation (M\&E) both internationally and country specific today; save Kenya. This is a very interesting and exciting development as the practice of M\&E can contribute to sound governance in a number of ways: improved evidence- 
based policy making (including budget decision making), policy development, management, and accountability (Nyonje, Ndunge, \& Mulwa, 2012).

Conservation projects, save solid waste management has become a source of income generation activity for urban youth as a platform for engaging with the broader politics of basic services that address the challenges of upsurge unemployment rate (Okot-Okumu, 2017). Scanty information is available on waste management in Nairobi, though it is reported that youth play a bigger role in assortment of solid waste management within Nairobi residential areas than the municipal government, (Odour, 2017). These are registered youth groups who are primarily waste pickers who provide residential door-to-door solid waste collection business services. Conservation livelihood ventures are designed to improve youths quality of life by improving their inclusion capacity to participate fully in all levels of social, economic and political activities, including improved physical well-being and access to social amenities and services through income generating activities for youth empowerment; equity issues and alleviating poverty that leads to ennui-; state of hopelessness among the youth (UNESCO, 2013).

\section{Objective of the Study}

The study was guided by the following objective: To examine how monitoring and evaluation practices effect performance of youth conservation livelihood projects in Nairobi County, Kenya.

\section{Research Question}

The study sought and answered the following research question: How does monitoring and evaluation practices effect performance of youth conservation livelihood projects in Nairobi County, Kenya?

\section{Research Hypothesis}

The study tested the following research hypothesis:

$\mathrm{H}_{0}$ : There is no significant relationship between monitoring and evaluation practices and performance of youth conservation livelihood projects in Nairobi County, Kenya.

\section{Literature Review}

In the last two decades, monitoring and evaluation literature reflects increasing attention to culture and cultural contexts; looking through the lens that judges the standards in to which outcomes are considered as real project outcomes, what values support the monitoring and evaluation practice and the measures of knowledge gained (Bagele, et.al., 2016). Monitoring and evaluation as a social learning intervention theory in this study context expounds largely on human behavior in terms of continuous reciprocal 
interaction between cognitive behavior and conservation influences (Patton, 2010). Data sources are the documentation tools, and locations for information that shows progress on youth conservation projects that include pre-posttests scores, program records (formative evaluation documents such as assessment reports), records from other Youth conservation livelihood projects stakeholders, and observations such as during focus groups discussions, interviews, or the conservation project itself (Villard, 2010).

In Nairobi, 45 percent of waste is managed by unemployed youth. (NEMA, 2015). Youth conservation government funded projects entails the involvement of unemployed young people in activities which have provision of conservation service that benefits the community with opportunities for personal development, accredited training and exit opportunities (Oduor, 2017). Registered youth groups in Nairobi engage in solid waste management projects, through garbage collection activities in varied residential zones which are categorized as government Youth conservation livelihood funded projects. They also collect various materials, recycle and re-sell them to improve their livelihood (YEDF, 2016). Monitoring and evaluation practices is therefore an effective process of facilitating data use for youth solid waste management processes, using culturally responsive monitoring and evaluation practices associated with assessment of waste management projects outcomes and impacts, analysis of processes, cost-effectiveness, implementation, and underlying theories of change, among other components of interest.

Dissemination of evaluation report involves the process of communicating either the procedures or the lessons learned from an evaluation in a consistent, unbiased, and timely manner (Carson-Cheng, and Jones, 2013), purpose being to ensure that utility by the potential evaluation users who are the youths group members, beyond those that have been involved in the evaluation process, are aware of the evaluation findings, conclusions and recommendations made. Monitoring leveraging technology entails mobile and social media applications to collect data; including use of geographic information system (GIS) technology (Carson-Cheng, and Jones, 2013), to map youth conservation projects. Adequate monitoring and evaluation practices ensures that effective information gathering procedures are chosen or often developed and implemented to ensure that the interpretation arrived at is valid for the intended use by project teams. (Rist, Bolly, and Martin, 2012). Data collected, processed, and reported in an evaluation should be systematically reviewed and any errors found should be corrected (Nyonje, Ndunge, and Mulwa, 2012).

Incentives during youth interventions evaluation findings to boost utility entails dissemination in detailed documented reports, stakeholders' workshops, news releases, press conferences and seminars, or social media 
communication. Application of evaluation results may include demonstrations through apparentiship in the industry (Kathryn, Hatry and Joseph, 2015). Studies that are carried out in Kenya shows that quite a number of youth livelihood ventures have been successful, especially various conservation projects in previous years that addressed the challenge of youth employment through adopting an Entrepreneurship Training Manual to facilitate youths conservation projects; through Youth Enterprise Development Fund loans (YEDF). Uwezo Fund loans (Government Youth funding Agency) funds solid waste management interventions including other youth conservation projects. On the other hand, several projects in Kenya have been informally cited as failed projects; meaning that they did not achieve the desired success. A significant share of the failed projects are government funded and donor funded, which usually undergo through heavy presence of monitoring and evaluation activities embedded on legal and donor requirement (Directorate of Youth, 2016)

The paradox in this study review is, despite a consensus among scholars that proper project monitoring and evaluation practices leads to project success, there are still cases of failing youth conservation projects in Kenya (Ochieng, Chepkuto, Tubey, and Kuto, 2012). Performance of many of the youth conservation projects in Kenya is inadequate, thus, alleviating poverty that leads to ennui-; state of hopelessness among the youth (UNESCO, 2013). This is irrespective of government funding, save Nairobi County which has more youths accessing government projects funding and training aggravated by proximity (Afon, 2012). The contest under this study was to investigate whether youth groups were engaging with the process of monitoring and evaluation as "researchers of their personal continuous practice" not as "mere data collectors". It therefore sought to investigate on the missing links leading to poor performance of youth groups' government funded conservation projects.

\section{Theoritical Framework}

Theory of Change is basically a comprehensive description and illustration of how and why a desired change is expected to happen in a particular context (Gujit, 2013). Theory of change in this research context is predominantly focused on assumptions that are anticipated to improve the already existing youth entrepreneurship manual for projects implementation into a more innovative design. The theory of change approach is by first identifying the desired long-term goals and then working backwards thus identifying all the awareness (outcomes) that must be in place (and how these may be related to one another causally) for the goals to occur (Brest, 2010). It is articulated in this study context by mapping out monitoring and evaluation practices to provide the basis for identifying the type of activity or intervention 
that may lead to performance outcomes for achieving the long-term goal; which includes the performance of youth solid waste management projects.

Through this approach, the precise link between activities, out puts, outcome and impacts that anticipated to lead to achievement of the long-term goals may be fully understood (Patton, 2010). The assumption of monitoring and evaluation of projects complexity theory of change is that it elaborates the design of the evaluation process to respect and protect the rights and welfare of the beneficiaries of a given intervention; including the ethical mandates of evaluators (Carol, 1995). This approach is assumed to lead to better evaluation, credibility of the findings, making it possible to measure progress indicators on achievement of future longer-term goals towards performance of youth conservation projects.

Research shows that the theory of change also expounds on evaluation ethics, like conflict of interest by evaluators to avoid compromising the evaluation processes and results. This includes evaluator's allocation and expenditure of resources that should reflect sound accountability procedures that are prudent and ethically responsible on expenditures (Lisa and Phillips, 2013).

The diversity of views derived through the theory of change links to the purpose of the this study in terms of youth cognitive aspects, and a value systems livelihood ventures towards the delineation of innovative solutions to youth conservation projects.

\section{Conceptual Framework}

This study was guided by the following conceptual framework that shows diagrammatized representation of the relationship between the variables. This is shown in Figure 1. 


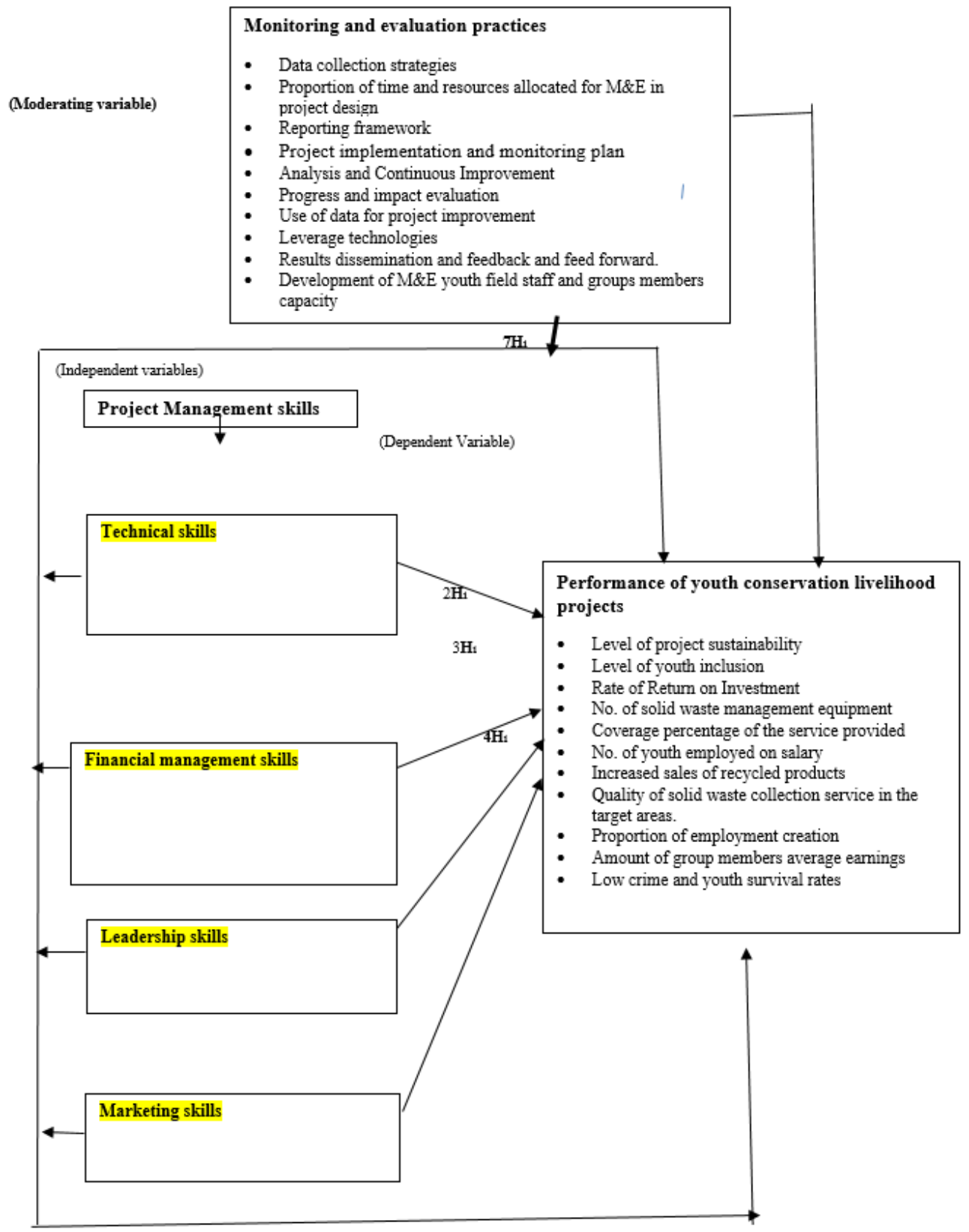

Figure 1: Conceptual framework on project management skills, monitoring and evaluation practices, and performance of youth environmental projects

\section{Research Methodology}

\section{Research paradigm and design}

The study used descriptive research and exploratory research designs. The research design enabled the collected information to be statistically inferred on the respondents. The study involved Participatory Action Research 
(PAR) approach which is a democratic process concerned with developing practical knowing and understanding based on emulated culture and values in the pursuit of worthwhile human purposes, grounded in a participatory worldview (McNamara, 2009). This allowed the researcher to provide deep insight into set study, as well as allowing more opportunities for the researcher to study innovative monitoring and evaluation practices prone to improving the performance livelihood projects.

\section{Study Population}

The study population was 700 youth groups members who included the urban youths in Nairobi County engaged in government funded solid waste management projects, drawn from the seventeen sub counties in Nairobi County.

\section{Sample size}

The sample size in this study was a selected representative sample from the accessible population to be studied and inference made to the larger population which was obtained using the Krejcie and Morgan table (1970). The sample size of 248 youths and sample strata table was calculated using proportionate Yamane method; (x/700*248); while the actual respondents from the number of youth members per group was homogenously selected using simple random sampling.

\section{Data Collection and administration}

Data was collected using questionnaire guide and an interview guide. The questionnaire guide was a list of standard questions to gather both qualitative and quantitative information from the scope of study using both open and close - ended questions. Open ended questions enabled the respondents to complete the questionnaire in their own views. Data was administered through Nairobi Sub County Officers in charge of the Youth conservation livelihood groups in Nairobi County using a list of youths from the sampled groups. Data collection process was expedited through holding youth group sites meetings with the respondents that enabled the researcher to administer the questionnaire through face to face interaction during the site visits. The researcher also conducted in-depth interviews through group discussions to garner empirical data from the respondents who were the heads of departments in the Directorate of Youth.

\section{Validity and reliability of the Instrument}

The researcher validated the research instruments through the assessment of validity which was subjected to a judgmental approach by the researcher's peers as recommended by Rist, 2012, for assessment to ensure 
that it included all the items that were necessary and eliminating detrimental items to a particular construct domain. To test reliability, 10 percent (Patton, 2008), twenty (25) respondents from the sample size were administered to the questionnaire. They were not involved in the actual research groups and they were excluded from final analysis. The researcher determined the internal consistency of Likert scale items using Cronbach's Alpha (Lee Cronbach's in 1951) at a score of between zero and one, with 0.7 generally accepted as a sign of acceptable reliability.

\section{Data presentation Method}

Data was presented by use of figures and tables which was a clear representation of monitoring and evaluation practices and Performance of Youth conservation livelihood ventures: Focus, Nairobi youth conservation projects, Kenya.

\section{Data analysis}

Preliminary data was edited, coded, cleansed and rechecked to minimize data entry errors. Qualitative data was analyzed and presented verbally based on themes, while quantitative data was analyzed descriptively using percentage frequencies, mean, and standard deviation. Inferentially, Pearson correlation coefficient and simple linear regression analysis was used to test hypotheses $\mathrm{P}=\beta 0+\beta 1 \mathrm{X} 1+\varepsilon$ where; $\beta 0$ and $\beta 1$ are constant/ regression parameters, $\mathrm{X} 1$ is the predictor variable (M\&E Practices) and $\varepsilon$ is the error term. T-test was used as a tool of analysis to test for significance level at 0.05 on the null hypothesis.

\section{Results of the Study}

\section{Monitoring and Evaluation Practices and performance of Youth conservation livelihood Projects}

This variable measured the extent to which monitoring and evaluation practices influenced the performance of youth conservation livelihood projects. In order to achieve this, the respondents were asked to give their options based on their level of agreements or disagreements based on a Likert scale in which a numerical scale of $1-5$ was provided where $1=$ strongly Disagree, 2=Disagree, $3=$ Neutral, 4=Agree and 5=Strongly Agree. The results were presented in Table 1.1 
Table 1.1 Monitoring and Evaluation Practices and performance of Youth conservation livelihood Projects

\begin{tabular}{l} 
Statements \\
\hline 1. My group has impact evaluation reports \\
over time on Project implementation \\
processes. \\
2. \\
The group holds evaluative consultative \\
profits and dividends \\
The most immediate results from our \\
group projects are the outputs indicators \\
which relates directly to our projects for \\
continued improvement. \\
We often hold consultative evaluation \\
dissemination meetings between the \\
group members and key informants and \\
other stakeholders on solid waste \\
management
\end{tabular}

5. We have recorded actual benefits and success stories by our group members as a result of outcomes achieved over time following the implementation of our conservation projects.

6. Group's strategic designs include allocation of time and budget framework for effective implementation.

7. Team leaders ensure information emerging from M\&E is fed back into our ongoing projects implementation and future planning.

8. Our project promotes stakeholders participation in all our project related activities

9. Project funders (GOK) has provided a common reporting framework and a standard M\&E guidance to systematically demonstrate project results

10. Customized application systems with project-specific indicators help team members track the project progress along a results chain to contribute to Vision 2030 social -economic pillars.

11. A systematic assessment of youth group projects implementation capacity and needs can inform government funding towards scaling up or replicating youth social- economic innovations.

$\begin{array}{ccccccc}\begin{array}{l}\text { Strongly } \\ \text { disagree }\end{array} & \text { Disagree } & \text { Neutral } & \text { Agree } & \begin{array}{c}\text { Strongly } \\ \text { agree }\end{array} & \text { Mean } & \begin{array}{c}\text { Std. } \\ \text { Deviation }\end{array} \\ 179(72.2) & 34(13.7) & 35(14.1) & 0 & 0 & 1.42 & .727 \\ & & & & & & \\ 11(4.4) & 4(1.6) & 38(15.3) & 167(67.3) & 28(11.3) & 3.79 & .831\end{array}$

$\begin{array}{lllllll}39(15.7) & 48(19.4) & 39(15.7) & 106(42.7) & 16(6.5) & 3.05 & 1.230\end{array}$

$\begin{array}{lllllll}2(.8) & 58(23.4) & 43(17.3) & 127(51.2) & 18(7.3) & 3.41 & 0.952\end{array}$

$\begin{array}{lllllll}7(2.8) & 118(47.6) & 12(4.8) & 111(44.8) & 0 & 2.92 & 1.017\end{array}$

$\begin{array}{lllllll}0 & 86(34.7) & 1(.4) & 28(11.3) & 133(53.6) & 3.84 & 1.382\end{array}$

$\begin{array}{lllllll}151(60.9) & 44(17.7) & 38(15.3) & 15(6.0) & 0 & 1.67 & 0.946\end{array}$

$\begin{array}{lllllll}53(21.4) & 88(35.5) & 16(6.5) & 68(27.4) & 23(9.3) & 2.68 & 1.326\end{array}$

$\begin{array}{lllllll}206(83.1) & 4(1.6) & 38(15.3) & 0 & 0 & 1.32 & 0.726\end{array}$

$\begin{array}{lllllll}50(20.2) & 17(6.9) & 51(20.6) & 114(46.0) & 16(6.5) & 3.12 & 1.259\end{array}$

$\begin{array}{lllllll}0 & 0 & 40(16.1) & 175(70.6) & 33(13.3) & 3.97 & 0.543\end{array}$ 
County. The results were presented in mean and standard deviation. Eleven statements were developed to measure the extent to which monitoring and evaluation practices influenced the performance of Youth conservation livelihood projects.

Statement 1 "My group has impact evaluation reports over time on Project implementation processes", majority of respondents 179 (72.2\%) strongly disagreed with the statement, 34(13.7\%) respondents agreed and $35(14.1 \%)$ were neutral. This line item had a mean score of 1.42 and a standard deviation of 0.727 which was lower than the composite mean of 2.83 and a standard deviation of 0.303 , implying that the statement negatively influence performance of Youth conservation livelihood projects in Nairobi County. The findings disagrees with previous literature reviewed in this study on relevant project management skills that include savings and investment and the relationship between each critical success factors towards the realization of profits for impact assessment (Carson Cheng, 2013). This findings depicts the respondent's status on investments which could be low or nothing at all. This implies that if youth group projects have to make impact, then something must done right from their inception to closure.

Statement 2 "The group holds evaluative consultative meetings on financial flows for shared profits and dividends", 167(67.3\%) respondents agreed with the statement, 28(11.3\%) strongly agreed, 38(15.3\%) were neutral, 11(4.4\%) respondents strongly disagreed while 4(1.6\%) disagreed. This line item had a mean score of 3.79 and a standard deviation of 0.831 which was higher than the composite mean of 2.83 and a standard deviation of 0.303 , implying that the findings positively influence performance of Youth conservation livelihood projects in Nairobi County. The findings concurs with study findings on the impetus of monitoring and evaluating budget to assess project performance (Carson- Cheng, 2013, which was also portrayed by the respondents in this study findings.

Statement 3 "The most immediate results from our group projects are the outputs indicators which relates directly to our projects for continued improvement", 106(42.7\%) respondents agreed with the statement, $16(6.5 \%)$ strongly agreed with the statement, 48 (19.4\%) disagreed while 39(15.7\%) while $39(15.7 \%)$. This line item had a mean score of 3.05 and a standard deviation of 1.230 which was higher than the composite mean of 2.83 and a standard deviation of 0.303 , implying that the statement positively influence performance of Youth conservation livelihood projects in Nairobi County. The findings concur with empirical study on complexity of evaluation which expounds on culturally responsive evaluation approaches (Bagele et. al., 2016). This confirms that youths perform tacit monitoring and evaluation regardless of formal M\&E systems within their projects as indicated by this study findings. 
Statement 4 "We often hold consultative evaluation dissemination meetings between the group members and key informants and other stakeholders on solid waste management", 127 (51.2\%) agreed, 18(7.3\%) strongly agreed, 58(23.4\%) disagreed, 2(0.8\%) strongly disagreed while $43(17.3 \%)$ were neutral. This line item had a mean score of 3.41 and a standard deviation of 0.952 which was higher than the composite mean of 2.83 and a standard deviation of 0.303 , implying that the statement positively influence performance of Youth conservation livelihood projects in Nairobi. This statement agrees with the exploratory study findings on monitoring and evaluation practices (Carson Cheng, 2013) that entails participatory approaches during project evaluation and dissemination, to enhance projects performance, which supports this study findings as well.

Statement 5 "We have recorded actual benefits and success stories by our group members as a result of outcomes achieved over time following the implementation of our conservation projects", 118 (47.6\%) respondents disagreed with the statement, $7(2.8 \%)$ strongly disagreed,111(44.8\%) agreed while $12(4.8 \%)$ were neutral. This line item had a mean score of 2.92 and a standard deviation of 1.017 which was higher than the composite mean of 2.83 and a standard deviation of 0.303 , implying that the statement positively influence performance of Youth conservation livelihood projects in Nairobi. This findings agrees with literature reviewed findings on factors influencing project success that entails timely data collection, documentation of reports and success stories including lessons learnt, which also supports the findings of this study.

Statement 6 "Group's strategic designs include allocation of time and budget framework for effective implementation", 133(53.6\%) respondents strongly agreed, 28(11.3\%) agreed with the statement, $86(34.7 \%)$ disagreed while $1(0.4 \%)$ respondents remained neutral. This line item had a mean score of 3.84 and a standard deviation of 1.382 which was higher than the composite mean of 2.83 and a standard deviation of 0.303 , implying that the findings positively influence performance of Youth conservation livelihood projects in Nairobi. This findings approves the empirical study findings on developmental evaluation (Patton, 2010) which concludes that effective monitoring and evaluation practices entails projects strategic designs with a budget frame work to determine cost effectiveness during project implementation. This findings agrees with this study findings as established from the respondent's responses which implies that Youth conservation livelihood groups have their tacit frame works and designs that guide their projects.

Statement 7 "Team leaders ensure information emerging from M\&E is fed back into our ongoing projects implementation and future planning", $151(60.9 \%)$ respondents strongly disagreed, 44(17.7\%) disagreed, 15(6.0\%) agreed, while 38(15.3\%) were neutral. This line item had a mean score of 1.67 
and a standard deviation of 0.946 which was much lower than the composite mean of 2.83 and a standard deviation of 0.303 , implying that the statement negatively influence performance of Youth conservation livelihood projects in Nairobi. This findings disagrees with the empirical study findings on managing effective evaluations which expounds on effects of stakeholders feedback and feed forward during project implementation (Rist, and Stame, 2006), implying that the respondents were not involved on projects processes; which support the findings of this study.

Statement 8 "Our project promotes stakeholders participation in all our project related activities", 88(35.5\%), disagreed with the statement, 53(21.4\%) strongly disagreed with the statement, 68(27.4\%) respondents agreed, 23(9.3\%) strongly agreed, while $16(6.5 \%)$ were neutral. This line item had a mean score of 2.68 and a standard deviation of 1.326 which was lower than the composite mean of 2.83 and a standard deviation of 0.303 , implying that the statement positively influence performance of Youth conservation livelihood projects in Nairobi. This findings disagrees with empirical study findings on stakeholder's engagement during project implementation by Patton, (2009) which elaborates on the impetus for bottom- up approach for project performance. This findings addresses the gap in knowledge in this study denoting that Youth conservation livelihood groups ought to engage with stakeholders to enhance their solid waste projects performance. This findings alludes to culturally responsive monitoring and evaluation practices where youths are mentored on project performance by other successful stakeholders through experiential learning.

Statement 9 "Project funders (GOK) has provided a common reporting framework and a standard M\&E guidance to systematically demonstrate project results", 206(83.1\%) respondents strongly disagreed with the statement, 4(1.6\%) respondents agreed while 38(15.3\%) were neutral. This line item had a mean score of 1.32 and a standard deviation of 0.726 which was much lower than the composite mean of 2.83 and a standard deviation of 0.303 , implying that the statement negatively influence performance of Youth conservation livelihood projects in Nairobi County. This findings support the empirical study findings by Rist, et.al.; 2012, on building of evaluation capacity to strengthen governance which describes the importance of a monitoring and evaluation policy framework by governments towards effect programme implementation.

Statement 10 "Customized application systems with project-specific indicators help team members track the project progress along a results chain to contribute to Vision 2030 social -economic pillars", 114(46.0\%) respondents agreed with the statement, 16(6.5\%) strongly agreed, 50(20.2\%) strongly disagreed, 17(6.9\%)respondents disagreed while 51(20.6\%) were neutral. This line item had a mean score of 3.12 and a standard deviation of 
1.259 which was higher than the composite mean of 2.83 and a standard deviation of 0.303 , implying that the statement positively influence performance of Youth conservation livelihood projects in Nairobi County. This findings agreed with empirical study findings on Utilization -focused evaluation using technology leverages (Quinn, 2008). The findings infers that customized application systems with project indicators can enhance performance on Youth conservation livelihood projects through application programmes for tracking systematic project results.

Statement 11 "A systematic assessment of youth group projects implementation capacity and needs can inform government funding towards scaling up or replicating youth social-economic innovations", 175(70.6\%) respondents agrees with the statement, 33(13.3\%) strongly agreed with the statement while $40(16.1 \%)$ were neutral. This line item had a mean score of 3.97 and a standard deviation of 0.543 which was much higher than the composite mean of 2.83 and a standard deviation of 0.303 , implying that the statement positively influence performance of Youth conservation livelihood projects in Nairobi. This statement agrees with empirical findings by Cummings, (2000) on results based management which expounds on Logic models that can be used as tools for systematic assessment of youth groups during project implementation. These he indicates are a viable monitoring and evaluation project evaluation practices to enable build capacity using participatory action approaches and in return thrush out youth capacity building needs to inform future funding. This findings also supports literature reviewed in this study on explanatory monitoring and evaluation knowledge and understanding on how project indictors accelerate development (Nyonge, Ndunge and Mulwa (2012), which can be replicated or funded on varied scope which affirms the respondents view in this study findings.

Response by the key informants when interviewed on monitoring and evaluation practices was cutting across various project management components particularly financial management and leadership skills. When asked concerning an existing Youth conservation livelihood monitoring and evaluation framework by the Directorate of youth, this is what he had to say;

"We have already existing monitoring and evaluation forms designed to track the implementation of youth projects. We monitor attendance of the youth trainings using a designed list of participant which does not necessarily capture disaggregated data. We monitor the training sessions, the mode of delivery and the environment on which the youth capacity building sessions takes place. We take data on the number of participants' attendance per training on life skills or on Core Business Training skills and key them on our Government provided Note pads; then send to the Headquarters for their analysis". 


\section{Inferential analysis of Monitoring and Evaluation Practices and performance of Youth conservation livelihood Projects}

Correlation, regression analysis and hypothesis testing were conducted to determine the relationship between Monitoring and Evaluation Practices and performance of Youth conservation livelihood Projects. These are further discussed in subsequent themes:

\section{Correlations Analysis of Monitoring and evaluation practices and Performance of Youth conservation livelihood Projects}

Table (1.2), the correlation output table shows that monitoring and evaluation practices characteristics were statistically significant (P-values under significant 2-tailed were all less than $\alpha=0.05$ ) towards performance of youth conservation livelihood projects.

Table 1.2 Correlations Analysis of Monitoring and evaluation practices and of Performance Youth conservation livelihood Projects

\begin{tabular}{cccc}
\hline & & Performance & MnEpractice \\
\hline $\begin{array}{c}\text { Performance } \\
\text { of Youth } \\
\begin{array}{c}\text { conservation } \\
\text { livelihood } \\
\text { projects }\end{array}\end{array}$ & $\begin{array}{c}\text { Pearson Correlation } \\
\text { Sig. (2-tailed) }\end{array}$ & 1 & $0.196^{* *}$ \\
& $\mathrm{~N}$ & 248 & 0.002 \\
& $* *$. Correlation is significant at the 0.01 level (2-tailed).
\end{tabular}

From table 1.2, the correlation index between monitoring and evaluation and performance was positive and significant, $r(247)=0.196$; $\mathrm{p} \leq 0.05$. This implies that as the level of monitoring and evaluation increases, the performance also increases.

Similarly, in order to determine the level of influence of monitoring and evaluation on performance, a regression analysis was performed on the variables as shown in table 1.3 on Regression analysis.

Table 1.3 Regression analysis of Monitoring and evaluation practices and Performance of Youth conservation livelihood Projects

Model Summary

\begin{tabular}{|c|c|c|c|c|c|c|}
\hline \multirow[t]{2}{*}{ Model } & \multirow{2}{*}{$\begin{array}{c}\mathrm{R} \\
\text { Square }\end{array}$} & \multirow{2}{*}{$\begin{array}{l}\text { Adjusted R } \\
\text { Square }\end{array}$} & \multirow{2}{*}{$\begin{array}{l}\text { Std. Error of the } \\
\text { Estimate }\end{array}$} & \multicolumn{3}{|c|}{ Change Statistics } \\
\hline & & & & $\begin{array}{l}\text { R Square } \\
\text { Change }\end{array}$ & $\begin{array}{c}\mathrm{F} \\
\text { Change }\end{array}$ & $\begin{array}{l}\text { Sig. F } \\
\text { Change }\end{array}$ \\
\hline 1 & 0.038 & 0.034 & 0.54041 & 0.038 & $9.777 \quad 1246$ & 0.002 \\
\hline
\end{tabular}

a. Predictors: (Constant), MnE practice

From this analysis, it was observed from the model summary table 0.196 with an $\mathrm{R}$ square of 0.38 implying that monitoring and evaluation practices variable could explain about 0.34 percent of the total variance in performance of youth project. This implies that monitoring and evaluation practices alone is not necessarily a good fit measure on performance. The 
findings established that 66 percent of the total variance is influenced by other culturally responsive monitoring and evaluation practices that are based on axiological philosophical paradigms that may collectively increase performance within a project significantly.

To test whether this model was significant in enabling predictions containing the moderating variable and dependent variable, the ANOVA table was produced and the results are as shown in Table 1.4

Table 1.4 ANOVA Table showing Regression Model of Monitoring and evaluation practices and Performance of Youth conservation livelihood Projects

\begin{tabular}{ccccccc}
\hline & Model & Sum of Squares & Df & Mean Square & F & Sig. \\
\hline \multirow{4}{*}{1} & Regression & 2.855 & 1 & 2.855 & 9.777 & $.002^{\mathrm{b}}$ \\
& Residual & 71.843 & 246 & .292 & & \\
& Total & 74.698 & 247 & & & \\
\cline { 2 - 7 } & & & & & &
\end{tabular}

a. Dependent Variable: Performance

b. Predictors: (Constant), MnEpractice

The ANOVA table showed that in the global model, monitoring and evaluation practices had significant prediction on performance of Youth conservation livelihood projects, This implied that the levels of monitoring and evaluation practices possessed by youths may be a good predictor of performance of youth conservation projects; though not very significant $\mathrm{F}(5,242)=9.777 \mathrm{p} \leq .05$

Table 1.5 Coefficientsa Regression table of Monitoring and evaluation practices and

Performance of Youth conservation livelihood Projects

\begin{tabular}{cccccc}
\hline Model & \multicolumn{2}{c}{ Unstandardized Coefficients } & $\begin{array}{c}\text { Standardized Coefficients } \\
\text { B }\end{array}$ & t & Sig. \\
\cline { 2 - 5 } & Std. Error & Beta & \\
(Constant) & 2.612 & .323 & & 8.086 & .000 \\
MnEpractice & .354 & .113 & .196 & 3.127 .002 \\
\hline
\end{tabular}

The Table 1.5 of regression coefficient showed that the unstandardised beta coefficient for: monitoring and evaluation practices to be 0.354 . The $\mathrm{T}$ value for monitoring and evaluation was significant, $\mathrm{T}(247)=3.127$.

\section{Hypothesis testing}

The study sought to investigate on Monitoring and evaluation practices and Performance of Youth conservation livelihood Projects. Pearson correlation coefficient was used to test the relationship between Monitoring and evaluation practices and Performance of Youth conservation livelihood Projects. This was done at $95 \%$ level of confidence. In order to prove the validity of this claim, both correlation and regression analysis were run on the SPSS programme version 22 based on the decision criterion that any P-value less than the threshold of $\alpha=0.05$ would be considered significant and subsequently lead to the rejection of the null hypothesis and acceptance of the 
alternative hypothesis or fail to reject the null hypothesis when the P-value obtained is greater than the threshold of $\alpha=0.05$ while failing to accept the alternative hypothesis. From the findings of regression and correlation analysis, it can be depicted that Monitoring and evaluation practices significantly influenced the level of performance of youth conservation project, $F(5,242)=9.777 \mathrm{p} \leq .05$. This therefore rejects the null hypothesis which stated that:

$\mathrm{H}_{0}$ : There is no significant relationship between monitoring and evaluation practices on performance of youth conservation projects in Nairobi; and accepted the alternative hypothesis: $\mathrm{H}_{1}$ : There is a significant relationship between monitoring and evaluation practices and performance of youth conservation projects in Nairobi County.

\section{Conclusion}

The objective in this study was basically to assess the extent to which monitoring and evaluation practices affect the performance of Youth conservation livelihood projects. The study findings provided the evidence that the level of performance increases as monitoring and evaluation practices intensifies, implying that levels of monitoring and evaluation knowledge and practices possessed by youths may be a good predictor of performance in projects implementation. Following statistical analysis, the study therefore concluded that there is a significant relationship between monitoring and evaluation practices and performance of Youth conservation livelihood projects.

\section{Recommendations}

Based on this finding, the following suggestions were recommended:

I. The study recommends monitoring and evaluation practices that include basic research; status assessment; and effectiveness measurement, performance evaluation framework, by developing a Theory of change Project Management Model (ToCPMM). The purpose of this performance model is to illustrate a sequence of causeand-effect relationships discussion between different stakeholders groups on the context any initiative seeks to influence including other actors able to influence change.

II. The study also recommends Policy actions by government to link youths to industry with an aim to learn, nature and practice monitoring and evaluation skills through mentorship programs from National and County firms public entities and other Corporates so as to incubate their skills for effective and gainful projects performance. 


\section{References:}

1. Afon, A. (2012). "A survey of operational characteristics, socioeconomic and health effects of scavenging activity in Lagos, Nigeria", Waste Management and Research, 30(7).Angen, M. J. (2000). Evaluating interpretive inquiry: Reviewing the validity debate and opening the dialogue. Qualitative Health Research

2. Awiti and Scott (2016); Aga Khan University Bruce Scott. The Kenya Youth Survey Report

3. Bagele Chilisa, Thenjiwe Emily Major, Michael Gaotlhobogwe \& Hildah Mokgolodi (2016): Decolonizing and Indigenizing Evaluation Practice in Africa: Toward African Relational Evaluation Approaches; University of Botswana.

4. Carlos Hernandez Ferreiro (2017): Monitoring and Evaluation and Learning Practices; the UCLG Capacity and Institution Building (CIB) Working Group: The Hague (Netherlands)

5. Carson-Cheng, E. \& Jones, M. (2013). Using Focus Groups to Enhance your Evaluation. Centre for Community Health and Evaluation, USA: Healthcare Community Georgia Foundation Publication.

6. Craig Valters, 2014, Theories of Change in International Development: Communication, Learning, or Accountability.

7. Dale, R. (2004). Evaluating development programmes and projects (2nd ed.). Thousand Oaks, California: Sage Publications Inc.

8. Directorate of Youth Affairs (2016); Ministry of Public Service, Youth and Gender Affairs

9. Hood, S. (2009). "Evaluation for and by Navajos: A Narrative Case of the Irrelevance of Globalization." In K. E. Ryan and J. B. Cousins (Eds.). The SAGE International Handbook of Educational Evaluation (pp. 447-463). Thousand Oaks, CA: Sage,

10. ILO (2017): Methodology of the global estimates of child labor, (Geneva, International Labor Organization.

11. Irene Gujit. (2013). Working with Assumptions in a Theory of Change Process TOC: Copyright 2016 Innovations for Poverty Action

12. Kathryn E. Newcomer, Harry P. Hatry and Joseph S. Wholey (2015) Handbook of Practical Program Evaluation, Fourth Edition.

13. McNamara, C. (2009). Basic Guide to Program Evaluation. (Retrieved from http://managementhelp.org/evaluatn/fnl_eval.htm.

14. Michael, B. (1994). Monitoring and evaluating social programs in developing countries, Washington D.C: World Bank:

15. Nyonje, R., Ndunge, D. \& Mulwa, S. A. (2012) Monitoring and Evaluation of Projects and Programs: A Handbook for Students and Practitioners. Nairobi: Aura Publishers. 
16. Oduor Stephen Okoth, Simeon Okelo, Fredrick Aila, Abiud Ochieng Awiti, Maria, Onyango, Martin Odhiambo Odera, Ogutu (2013) Effects of the Youth Enterprise Development Fund on Youth Enterprises in Kenya; Journal article

17. Okot-Okumu, J. (2017). Solid waste management in African citiesEast Africa. In L. F. Marmolejo Rebello; (Ed.), Waste managementan integrated vision. Available [online]: http://www.intechopen.com/books/waste-management-an-integratedvision/solid-waste-management/. (16/02/2018).

18. Patton, M. Q. (2002). Qualitative Research \& Evaluation Methods. 3rd edition. Sage Publications, Inc.

19. Patton, M. Q. (2010). Developmental Evaluation: Applying Complexity Concepts to Enhance Innovation and Use. New York: Guilford Press.

20. Rist, R. C., \& Stame, M. (2006). .From studies to streams: Managing evaluation systems; comparative policy evaluations volume XII. New Jersey: Transaction publishers.

21. Rist, R. C., Bolly, M. H., \& Martin, F. (2012). Influencing change: Building of evaluation capacity to strengthen governance. Washington DC: World Bank.

22. Villard, J. A. (2010). Use of Focus Group: An Effective Tool for Involving People in Measuring Quality and Impact. Leadership educators.org Villard retrieved on 6th March 2017 Vol. 29(1), 48 - 82. 